\title{
Correction to: Two New Co(II) Complexes of Picolinate: Synthesis, Crystal Structure, Spectral Characterization, a-Glucosidase İnhibition and TD/DFT Study
}

\author{
Sümeyye Altürk ${ }^{1} \cdot$ Davut Avcı $^{1} \cdot$ Belma Zengin Kurt ${ }^{2} \cdot$ Ömer Tamer $^{1} \cdot$ Adil Başoğlu $^{1} \cdot$ Fatih Sönmez $^{3} \cdot$ Yusuf Atalay $^{1}$. \\ Necmi Dege 4
}

Published online: 25 August 2021

(c) Springer Science+Business Media, LLC, part of Springer Nature 2021

\section{Correction to: Journal of Inorganic and Organometallic Polymers and Materials (2019) 29:1265-1279 https://doi.org/10.1007/s10904-019-01090-7}

The original version of this article unfortunately contained a mistake. The authors regret that the project number as stated in the Acknowledgement was incorrect. It should read (Project Number: MFAG-117F234) and not (Project Number: MFAG-117F235). The authors would like to apologise for any inconvenience caused.

The corrected Acknowledgements is given as follows.
Acknowledgements This work was supported by the Scientific and Technological Research Council of Turkey (TÜBITAK) (Project Number: MFAG-117F234).

Publisher's Note Springer Nature remains neutral with regard to jurisdictional claims in published maps and institutional affiliations.

The original article can be found online at https://doi.org/10.1007/ s10904-019-01090-7.

Sümeyye Altürk

sumeyye-alturk@hotmail.com

$\triangle$ Davut Avcı

davci@sakarya.edu.tr

1 Department of Physics, Faculty of Arts and Sciences, Sakarya University, 54187 Sakarya, Turkey

2 Department of Pharmaceutical Chemistry, Faculty of Pharmacy, Bezmialem Vakif University, 34093 Istanbul, Turkey

3 Department of Chemistry, Faculty of Arts and Sciences, Sakarya University, 54187 Sakarya, Turkey

4 Department of Physics, Faculty of Arts and Sciences, Ondokuz Mayıs University, 55139 Samsun, Turkey 